\title{
SENSITIVITY STUDY OF AIRPLANE IMPACT ON AN UNDERGROUND RADIOACTIVE WASTE-STORAGE BUILDING
}

\author{
ANDRII NYKYFORCHYN ${ }^{1}$, MILKO MILOSHEV ${ }^{2}$, MARIN KOSTOV $^{2} \&$ JENS-UWE KLÜGEL $^{1}$ \\ ${ }^{1}$ NPP Goesgen-Daeniken AG, Switzerland \\ ${ }^{2}$ Risk Engineering Ltd., Bulgaria
}

\begin{abstract}
A hypothetical crash of a military aircraft F-4 onto an underground radioactive waste storage was studied. The primary objective was to evaluate the amount of fuel that could penetrate the roof of the building. The dynamic analyses of the impact of the airplane on the RC roof slab covered with asphalt concrete layer were performed with an integral simulation approach. The finite element model of the airplane includes detailed modelling of fuselage, wings, engine and non-structural parts. Fuel is modelled as SPH particles, which allows evaluation of the fuel dispersion and penetration. Sensitivity of the concrete roof damage and fuel penetration on various model and impact parameters is extensively studied. Different material models of concrete, asphalt concrete and aluminium airplane structure were investigated. The effect of the impact location, velocity and angle was studied. The comparison of the analyses with different input parameters showed different sensitivity of the damage degree of the building and the amount of the penetrated fuel. The impact location and the material modelling of the reinforced concrete and airplane structure have a relatively small effect on the fuel penetration. The amount of the penetrated fuel depend strongly on the impact velocity and impact angle. Incorporation of the asphalt concrete layer in the structural model has also a significant impact on the roof damage and the fuel penetration.
\end{abstract}

Keywords: airplane impact, concrete structure, nuclear facility, smooth particle hydrodynamics.

\section{INTRODUCTION}

In the study [1] NPP Gösgen has evaluated a hypothetical military aircraft crash (MAC) on the underground low and intermediate level radioactive waste (LLW and ILW) storage building and the resulting kerosene fire and radiological consequences. The impact was expected to create a breach in the roof of the building and project debris and kerosene from the aircraft into the building. A structural analysis of the impact of MAC on the ILW building was performed providing estimation of the hole size and kerosene mass entering the building. Next detailed fire analyses based on a Computational Fluid Dynamics (CFD) methodology were performed. It was found out that the kerosene fire would not cause significant damage to the LLW and ILW waste barrels that could lead release of the radioactive materials.

The type of the aircraft, the impact velocity and angle in the earlier study [1] were based on the design requirements to the nuclear facility. Some of the assumptions and analysis parameter were conservative, others were based on realistic estimations. In current paper additional mechanical analyses of the airplane impact are presented, which show the sensitivity of the structural damage and the fuel penetration amount to various impact configurations and analysis parameters. The computations of the impact dynamics were performed with the explicit FE solver LS-DYNA. 


\section{AIRCRAFT IMPACT MODELLING}

\subsection{Airplane model}

The detailed LS-DYNA model of the aircraft was developed and discussed in detail in [1]. The total mass of the aircraft is $19 \mathrm{t}$, which includes $4.8 \mathrm{t}$ of fuel. In order to evaluate the dispersion and penetration of fuel it was modelled as SPH (Smooth Particle Hydrodynamics) particles. The approach for modelling aircraft fuel using SPH is described in [2]. The total number of 1,114 particles were spaced at $d=0.15 \mathrm{~m}$ in the fuel tanks. Accordingly to the SPH formulation in LS-DYNA, the kernel function $W$ is defined as $W(x, h)=\theta(x) / h(x)^{3}$, where $\theta(x)$ is the cubic B-spline function and $h(x)$ is the smoothing length. In the performed analyses the smoothing length is set initially to $h_{i}=1.25 \mathrm{~d}$ and varies in time and in space between $0.2 h_{i}$ and $2.0 h_{i}$.

The structure of the airplane is built entirely of shell elements. The FE model of the airplane was validated by performing finite element impact analyses into rigid wall and moveable concrete block [1].

The material properties of the airplane structure were assumed to be those of a typical aluminium alloy 2024-T3, while the bilinear kinematic hardening model (MAT003) was used. The dynamic increase of the material strength due to strain rate effects is considered by using the Cowper-Symonds strain rate model. The material properties of the SPH correspond to water.

The Johnson-Cook constitutive model (MAT015 in LS-DYNA) was implemented to simulate the strain rate dependent material behaviour. The flow stress and the fracture strain are determined from

$$
\begin{gathered}
\sigma=\left(A+B \varepsilon^{n}\right)\left(1+C \ln \left(\frac{\dot{\varepsilon}}{\dot{\varepsilon}_{0}}\right)\right) \\
\epsilon_{f}=\left(D_{1}+D_{2} e^{D_{3} \frac{p}{\sigma}}\right)\left(1+D_{4} \ln \left(\frac{\dot{\varepsilon}}{\dot{\varepsilon}_{0}}\right)\right) .
\end{gathered}
$$

The JC model parameters for the aluminium 2024-T3 alloy $C=0.0083, D_{1}=0.13$, $D_{2}=0.13, D_{3}=-1.5, D_{4}=0.07$ were taken from [3]. The rate independent parameters $A=$ $300 \mathrm{MPa}, B=360 \mathrm{MPa}, n=0.25$ and $\varepsilon_{\text {fmin }}=0.2$ were obtained by fitting the strain-stress curve of 2024-T3 alloy at low strain rate. If the failure strain $\varepsilon_{\text {fmin }}$ is exceeded, those elements are eroded.

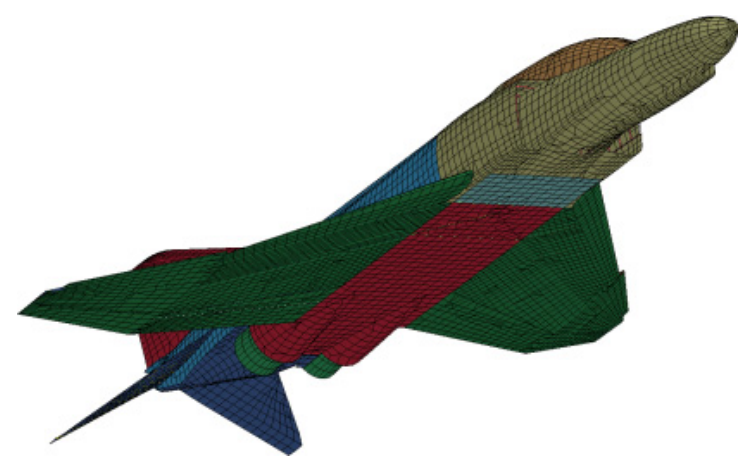

Figure 1: FE model of F4 "Phantom". 


\subsection{Target structure model}

The model of the target structure is shown in Fig. 2. In addition to the RC structure of the building, the soil surrounding the underground structure, as well as the asphalt layer on top are also included. The concrete structure and the asphalt were modelled with 3D solid elements, while the steel rebars were modelled with beam elements. The asphalt layer is assumed to be perfectly tied to the concrete structure by using common nodes for the concrete and asphalt elements.

Continuous Surface Cap Model (MAT159 CSCM Concrete in LS-Dyna) was used for the concrete material. The CSCM model parameters were calculated based on the concrete compression strength, aggregate size and density. The essential erosion coefficient is a fitting parameter, obtained by matching the numerical simulation results of the VTT impact tests to the test results (residual velocity and the concrete damage pattern) [4].

Plastic kinematic hardening model (LS-Dyna MAT003) is used for steel rebars. The rebar elements are eroded when the failure strain of 0.2 is achieved.

The material model of Drucker-Prager (DP, MAT193 in LS-Dyna) was used for the asphalt concrete material, see [1], [5], [6]. The main parameters of the DP material are the internal friction angle $\phi$, the cohesion $c$ and the shear modulus $G$. The friction angle of $\phi=26^{\circ}$ at $\mathrm{T}=10^{\circ} \mathrm{C}$ was taken from [7] and [8]. The cohesion can be determined from eqn (3) if the asphalt compressive strength $f_{c}$ is known, [9]:

$$
f_{c}=\frac{2 \cdot c \cdot \cos \varphi}{1-\sin \varphi} \text {. }
$$

The asphalt compressive strength depends on the temperature $T$ and the strain rate $\dot{\varepsilon},[10]$ :

$$
f_{c}=-108\left(1-\frac{1}{1+\left(\dot{\varepsilon} e^{-86.3+24260 / T}\right)^{0.32}}\right) \text {. }
$$

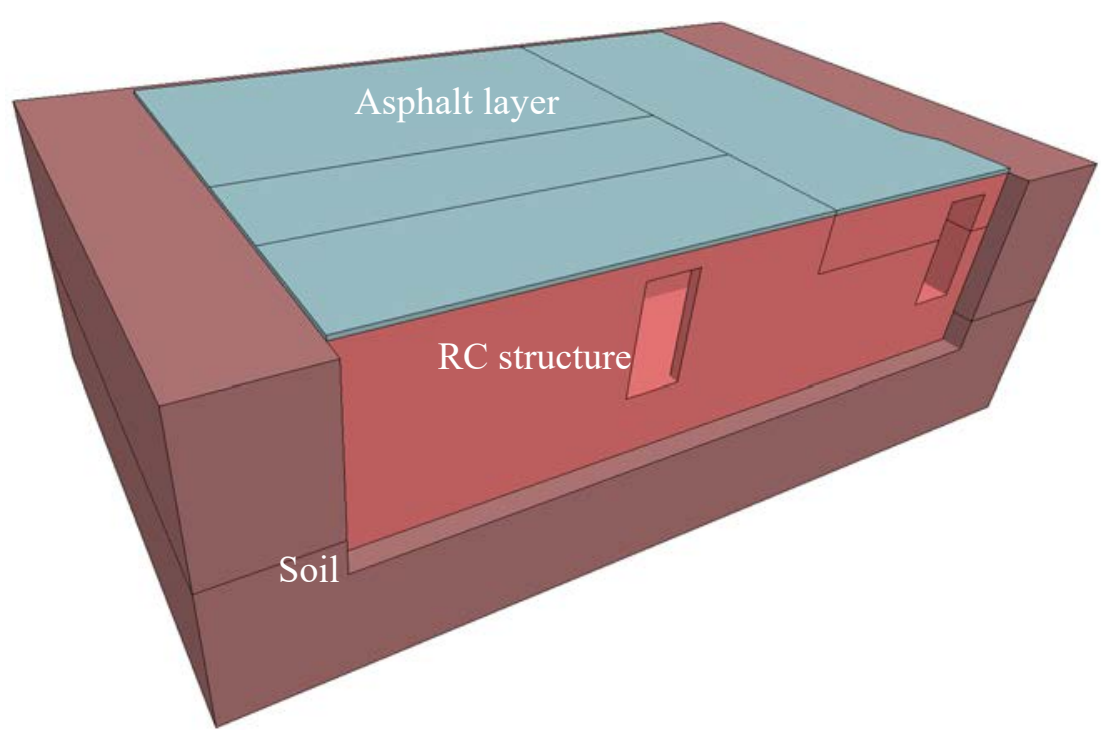

Figure 2: FE Model of the impact target. 
Under the conservative assumption that the material strain rate during the impact is $\dot{\varepsilon}=$ $1 / \mathrm{s}$, the compressive strength of $48 \mathrm{MPa}$ at $10^{\circ} \mathrm{C}$ was used in the analyses. The cohesion coefficient of $15.2 \mathrm{MPa}$ was calculated from eqn (3) with the friction angle and the compressive strength determined above.

\subsection{Impact simulation and load cases}

The impact is modelled by assigning the initial velocity of the airplane and defining the contact between the airplane parts and the building structure parts, including self-contact, as a single surface contact (*CONTACT_ERODING_SINGLE_SURFACE). The friction coefficient of 0.5 was set for the sliding surfaces. The mass of the eroded elements was retained by distributing the mass to the corner nodes via option ENMASS $=2$ in *CONTROL CONTACT.

In the baseline analysis case, the airplane impacts the structure in the direction normal to the surface at the initial velocity of $215 \mathrm{~m} / \mathrm{s}$. The impact position was assumed to be in the middle of the slab (Fig. 3).

The most important outcome of the impact analyses is the fuel amount that goes through the penetration hole and burns inside the building. The kerosene mass was determined by counting the number of SPH particles, which disperse in the compartment below the concrete slab. Those SPH particles that stay within the penetration zone above the damaged concrete are not taking into account. Theoretically, the fuel can pass through the cracked concrete to the compartment. However, it is assumed that the cracks in the structure would be plugged by the structure and plane debris, so that this part of fuel will fully burn outside the building.

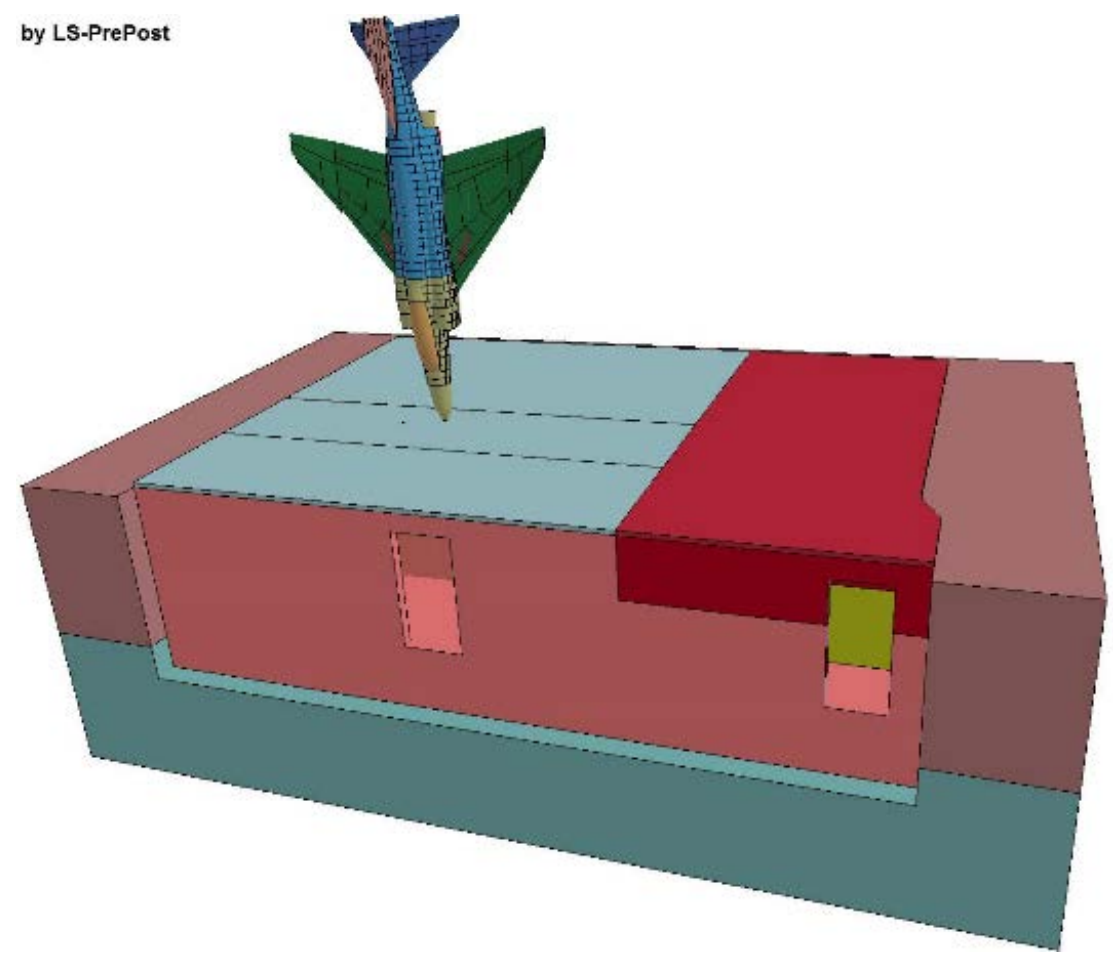

Figure 3: Impact simulation: initial setup. 


\section{IMPACT SIMULATION RESULTS}

\subsection{Impact velocity}

The impact simulation at $215 \mathrm{~m} / \mathrm{s}$ is visualized in Fig. 4. The airplane structure is disengaged during the impact, while the fuel disperses outside and inside the building (Fig. 5).

The impact velocity was subsequently reduced from the design value of $215 \mathrm{~m} / \mathrm{s}$ with a step of $5 \mathrm{~m} / \mathrm{s}$ until there is no fuel penetration. The results are summarized in Table 1 .

At $170 \mathrm{~m} / \mathrm{s}$ the concrete reinforcement deforms but does not crack (Fig. 6). No concrete is eroded, thus no SPH particle penetrate into the compartment (Fig. 7). This is assumed to be the critical speed for the fuel penetration.

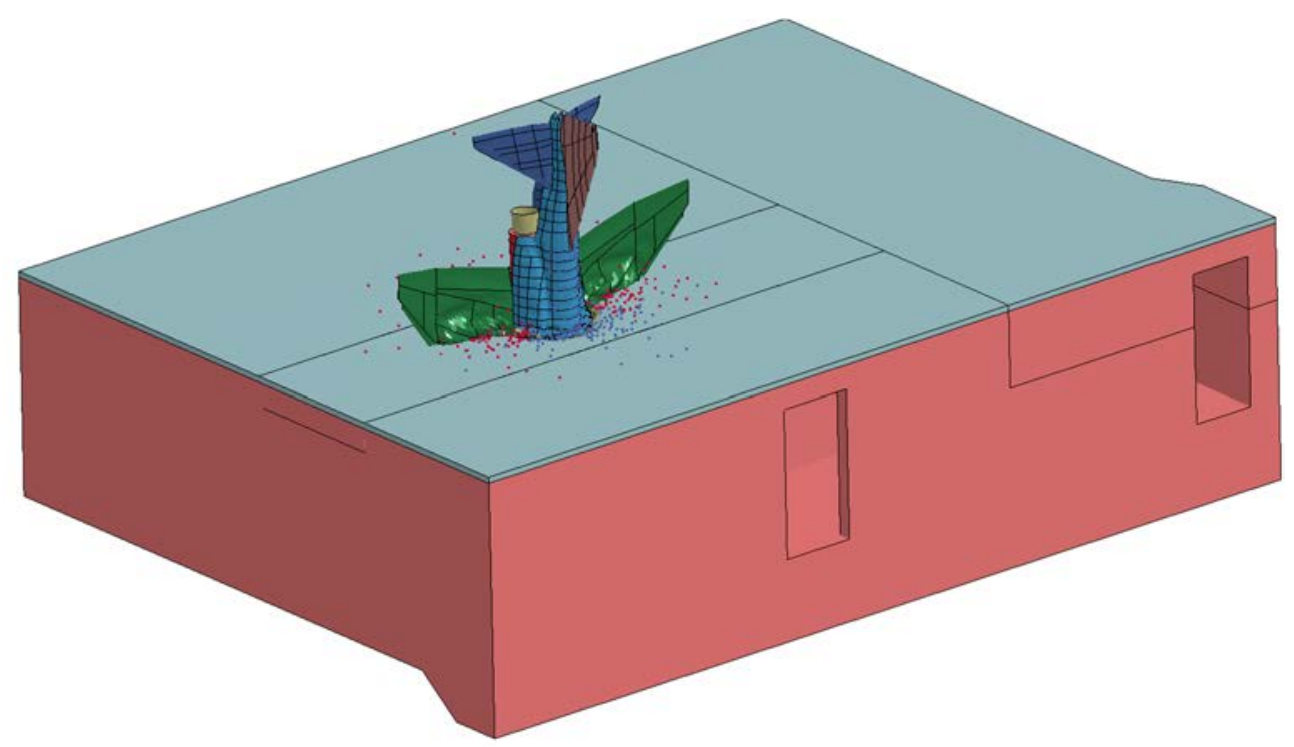

Figure 4: Impact simulation: airplane destruction.

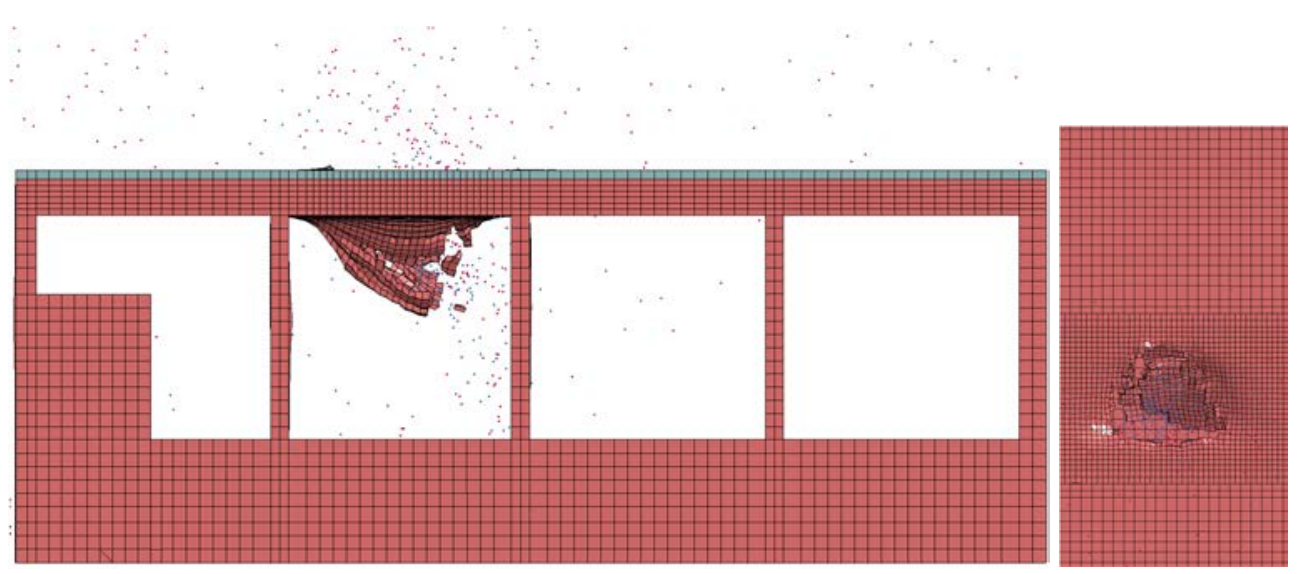

Figure 5: Concrete perforation and fuel penetration at $215 \mathrm{~m} / \mathrm{s}$. 
Table 1: Structural damage and fuel penetration at different impact velocities.

\begin{tabular}{|l|c|c|c|c|c|c|c|c|}
\hline & \multicolumn{7}{|c|}{ Impact velocity, m/s } \\
\cline { 2 - 9 } & 170 & 175 & 185 & 190 & 195 & 200 & 205 & 215 \\
\hline Asphalt & Deformed & Cracked & Perforated & Perforated & Perforated & Perforated & Perforated & Perforated \\
\hline Concrete & Deformed & Eroded & Eroded & $\begin{array}{c}\text { Heavily } \\
\text { eroded }\end{array}$ & $\begin{array}{c}\text { Heavily } \\
\text { eroded }\end{array}$ & $\begin{array}{c}\text { Heavily } \\
\text { eroded }\end{array}$ & $\begin{array}{c}\text { Fully } \\
\text { perforated }\end{array}$ & $\begin{array}{c}\text { Fully } \\
\text { perforated }\end{array}$ \\
\hline Reinforcement & $\begin{array}{c}\text { Top } \\
\text { rebars } \\
\text { cracked }\end{array}$ & Cracked & Cracked & Cracked & Cracked & Cracked & Cracked & Cracked \\
\hline $\begin{array}{l}\text { Penetrated fuel } \\
\text { mass, kg }\end{array}$ & 0 & 20 & 85 & 75 & 60 & 55 & 550 & 600 \\
\hline
\end{tabular}

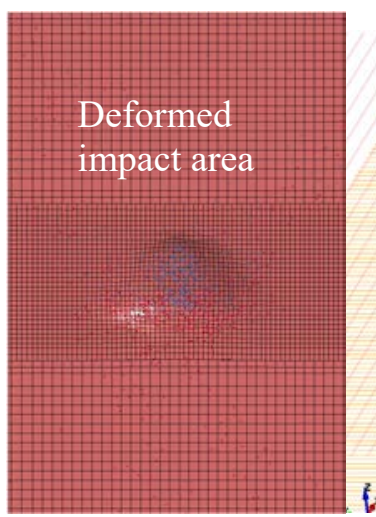

Deformed top reinforcement

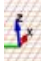

\section{Deformed bottom} reinforcement

Figure 6: Reinforced concrete deformation at $170 \mathrm{~m} / \mathrm{s}$.

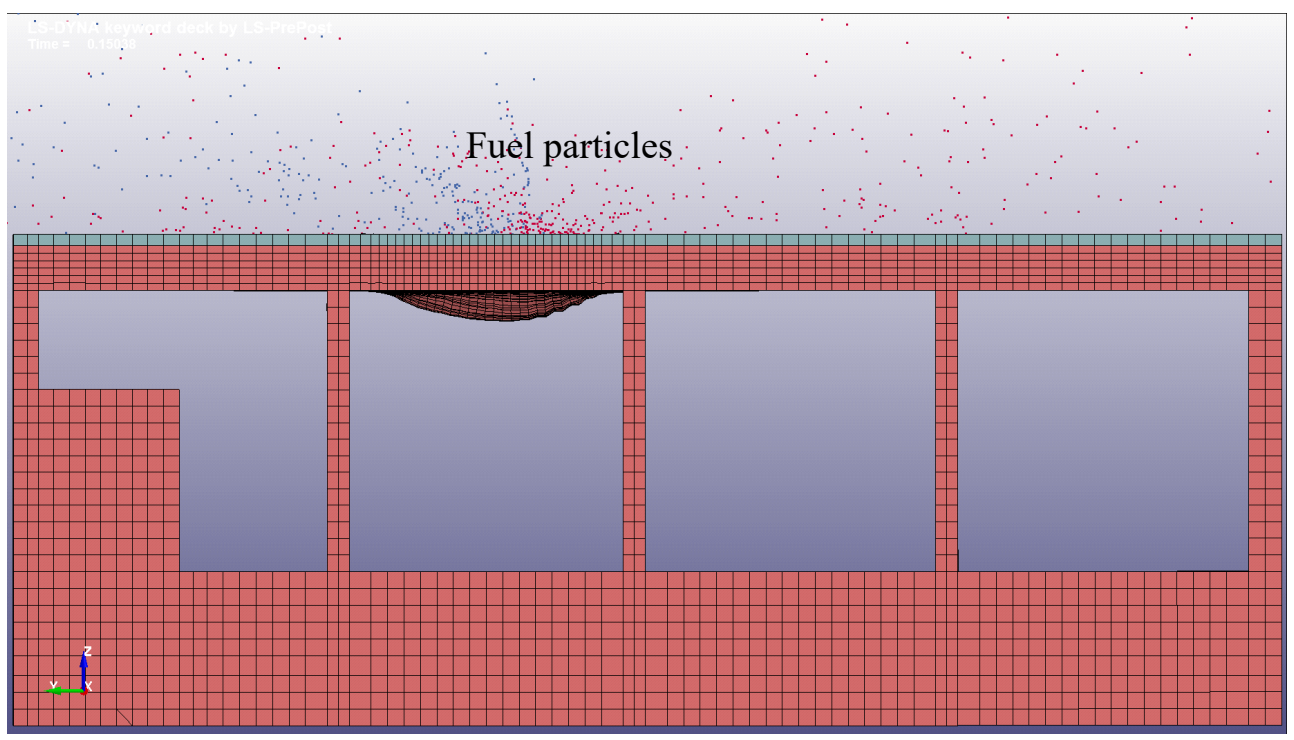

Figure 7: Fuel dispersion at $170 \mathrm{~m} / \mathrm{s}$. 
At $175 \mathrm{~m} / \mathrm{s}$ the reinforcement starts to crack and a small hole appear in the concrete roof (eroded concrete elements), but only $20 \mathrm{~kg}$ of fuel particles penetrate into the building. Such a small amount of fuel would probably be mixed with the debris and should not cause fire in the compartment. Therefore the critical velocity for local fire initiation is set to $175 \mathrm{~m} / \mathrm{s}$.

At the impact velocity of $185 \mathrm{~m} / \mathrm{s}$ and $200 \mathrm{~m} / \mathrm{s}$ the amount of the penetrated fuel increases to $85 \mathrm{~kg}$. Then the calculated fuel mass actually decreases with increased velocity up to $200 \mathrm{~m} / \mathrm{s}$. Possible explanation is that at higher impact energy the fuel release may happen before the perforation occurs and the fuel disperses outside the concrete structure. Thus, higher impact velocities do not necessary cause more damage in terms of fire.

Above $205 \mathrm{~m} / \mathrm{s}$ the concrete perforation occurs, so that much more fuel enters the plenum and causes vast fire. The amount of fuel does not increase much until $215 \mathrm{~m} / \mathrm{s}$.

\subsection{Impact angle}

The airplane impact at various impact angles between $90^{\circ}$ and $60^{\circ}$ at the impact velocity of $215 \mathrm{~m} / \mathrm{s}$ was investigated. The airplane axis was assumed the same as the impact axis (Fig. 8).

At impact angle of $60^{\circ}$ no fuel penetration occurs, Fig. 8. Here the vertical component of the impact velocity is $186 \mathrm{~m} / \mathrm{s}$, which is higher that the critical fuel penetration velocity of $170 \mathrm{~m} / \mathrm{s}$ at $90^{\circ}$ impact. The impact energy is spread over the larger impact area at an inclined impact, which significantly reduces damage due to punching.

The summary of the results in Table 2 shows that the amount of the penetrated fuel decreases rapidly by decreasing the impact angle.

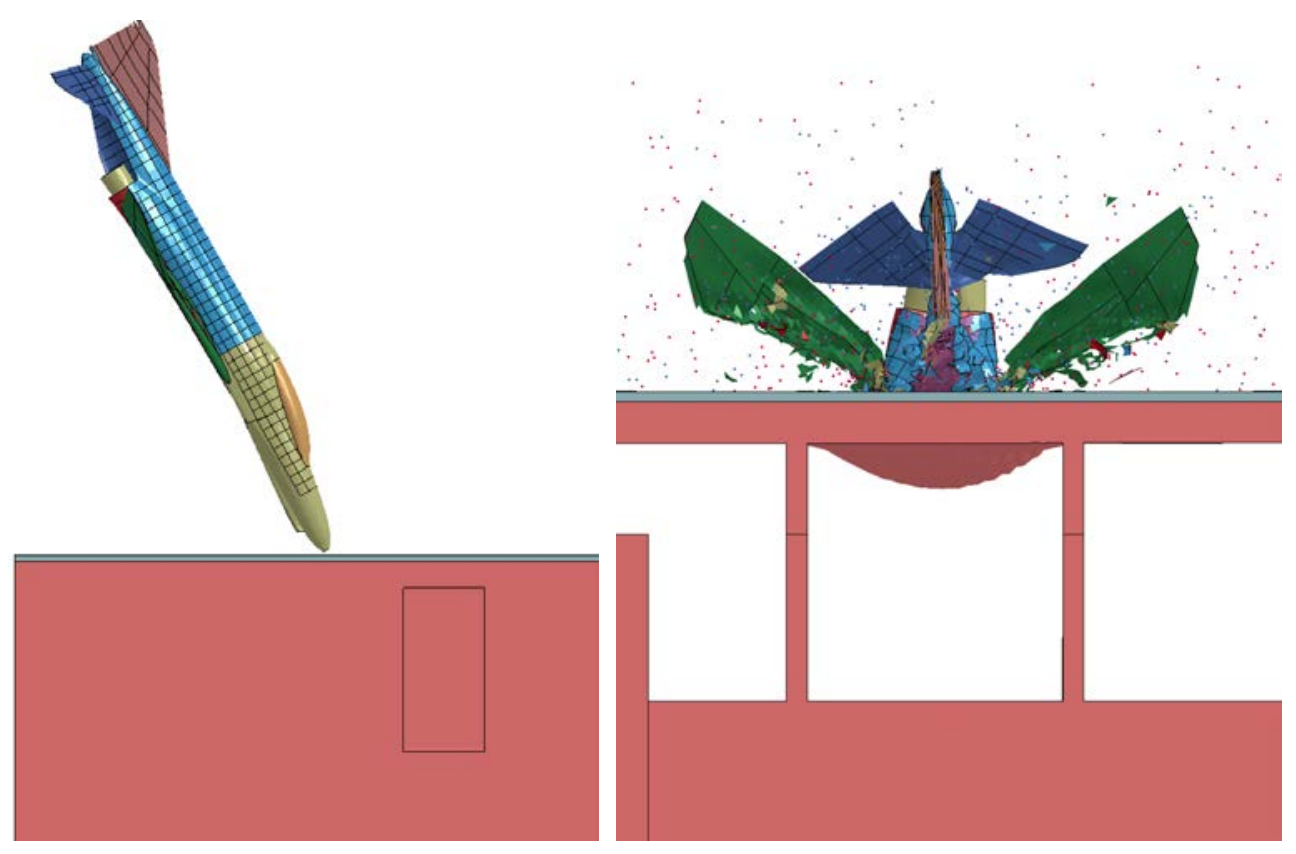

Figure 8: Beginning and end of the impact at $60^{\circ}$. 
Table 2: Structural damage and fuel penetration at different impact angles.

\begin{tabular}{|l|c|c|c|c|c|c|}
\hline \multirow{2}{*}{} & \multicolumn{6}{|c|}{ Impact angle, ${ }^{\circ}$} \\
\cline { 2 - 7 } & 60 & 65 & 70 & 75 & 80 & 90 \\
\hline Asphalt & Deformed & Cracked & Perforated & Perforated & Perforated & Perforated \\
\hline Concrete & Deformed & Eroded & Eroded & $\begin{array}{c}\text { Heavily } \\
\text { eroded }\end{array}$ & $\begin{array}{c}\text { Fully } \\
\text { perforated }\end{array}$ & $\begin{array}{c}\text { Fully } \\
\text { perforated }\end{array}$ \\
\hline Reinforcement & $\begin{array}{c}\text { Top rebars } \\
\text { cracked }\end{array}$ & Cracked & Cracked & Cracked & Cracked & Cracked \\
\hline Penetrated fuel mass, kg & 0 & 10 & 35 & 85 & 350 & 600 \\
\hline
\end{tabular}

\subsection{Impact position}

The airplane was rotated $90^{\circ}$ in respect to the impact axis, so that the wings of the airplane hit the compartment walls, Fig. 9. The results of the analyses at $215 \mathrm{~m} / \mathrm{s}$ show that this have no effect on the overall impact resistance, so that the amount of penetrated fuel does not significantly change. The additional resistance, which was provided by the walls, did not reduce much the residual impact energy after the wings were damaged.

\subsection{Concrete material model}

The comparison of concrete damage models is extensively studies in the literature [11], [12]. In this study, the CSCM model for the concrete was replaced by the Karagozian and Case model (K\&C, MAT_072R3 in LS-Dyna) [13]. The model parameters were generated automatically by LS-DYNA with the simplified input of the unconfined compression strength $f_{c}=50 \mathrm{MPa}$ and LOCWIDTH $=0.09 \mathrm{~m}$ corresponding to the grain size of $0.03 \mathrm{~m}$. The erosion criterion remained at $50 \%$ strain.

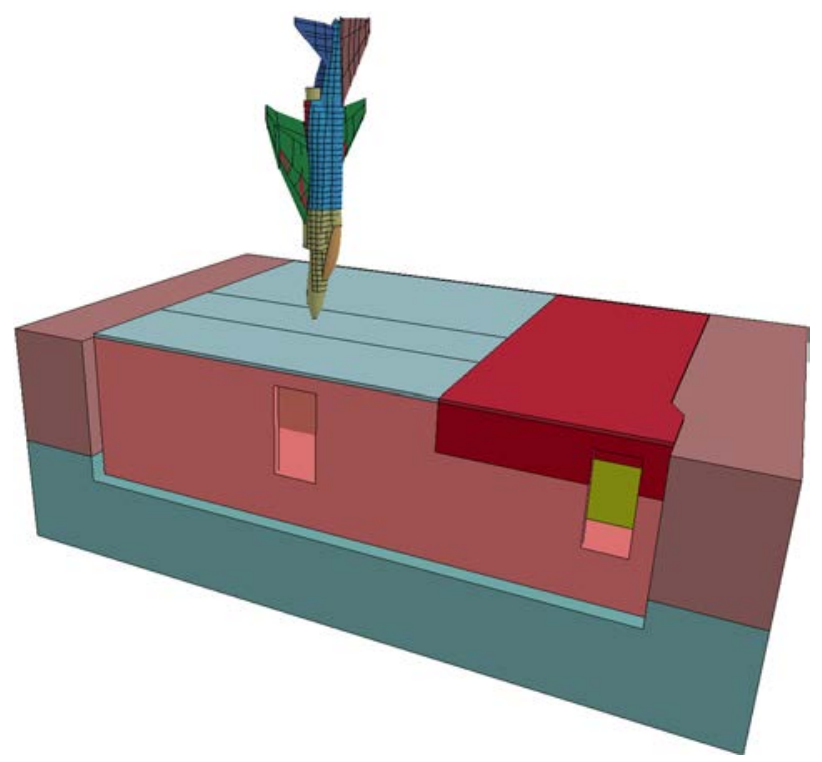

Figure 9: Airplane rotated $90^{\circ}$ about the impact axis. 
In comparison to the CSCM model, where viscoplastic strain rate effects are implemented internally, the $\mathrm{K} \& \mathrm{C}$ model uses external strain rate curves. In current study, the strain rate effects were automatically included by setting the option LCRATE $=-1$, which calculates dynamic increase factor (DIF) based on equations provided in [11]. The equations for compression are based on the CEB data [14]

$$
\begin{aligned}
D I F & =\left(\frac{\dot{\varepsilon}}{\dot{\varepsilon}_{s}}\right)^{1.026 \alpha}, \\
\alpha & =\frac{1}{5+9 f_{c} / f_{c 0}},
\end{aligned}
$$

where $\dot{\varepsilon}_{s}=3 \times 10^{-5} / \mathrm{s}$ is the reference "static" strain rate and $f_{c 0}=10 \mathrm{MPa}$ is the reference compressive strength. Similar equations are provided in [11] for tension.

The comparison of the concrete damage at the impact velocity of $170 \mathrm{~m} / \mathrm{s}$ showed slightly stronger deformation of the concrete with the K\&C model. Some rebars of the top reinforcement are cracked, but still there is no fuel penetration in the compartment.

The results of the analyses performed at the impact velocity of $190 \mathrm{~m} / \mathrm{s}$ showed again a higher deformation of the impacted zone for the $\mathrm{K} \& \mathrm{C}$ model. However, the damaged concrete structure has smaller openings, which resulted in lower amount of fuel penetration.

\subsection{Asphalt concrete material model}

As mentioned before, the compressive strength of asphalt increases with the strain rate. The results of the impact analyses show that the peak strain rate of asphalt during the short time period of failure is an order of magnitude higher than the original conservative assumption of $\dot{\varepsilon}=1 / \mathrm{s}$ (Fig. 10). In this sensitivity study case, a more realistic assumption of $\dot{\varepsilon}=10 / \mathrm{s}$ was made. According to eqns (3) and (4) this results in higher compressive strength $f_{c}=68 \mathrm{MPa}$ and increased cohesion coefficient $c=21.3 \mathrm{MPa}$ in the Drucker-Prager material model.

The higher material strength of the asphalt layer has an immediate impact on the impact resistance of the whole structure. There is no damage of the asphalt and concrete structure and no fuel penetration at the impact velocity of $190 \mathrm{~m} / \mathrm{s}$.

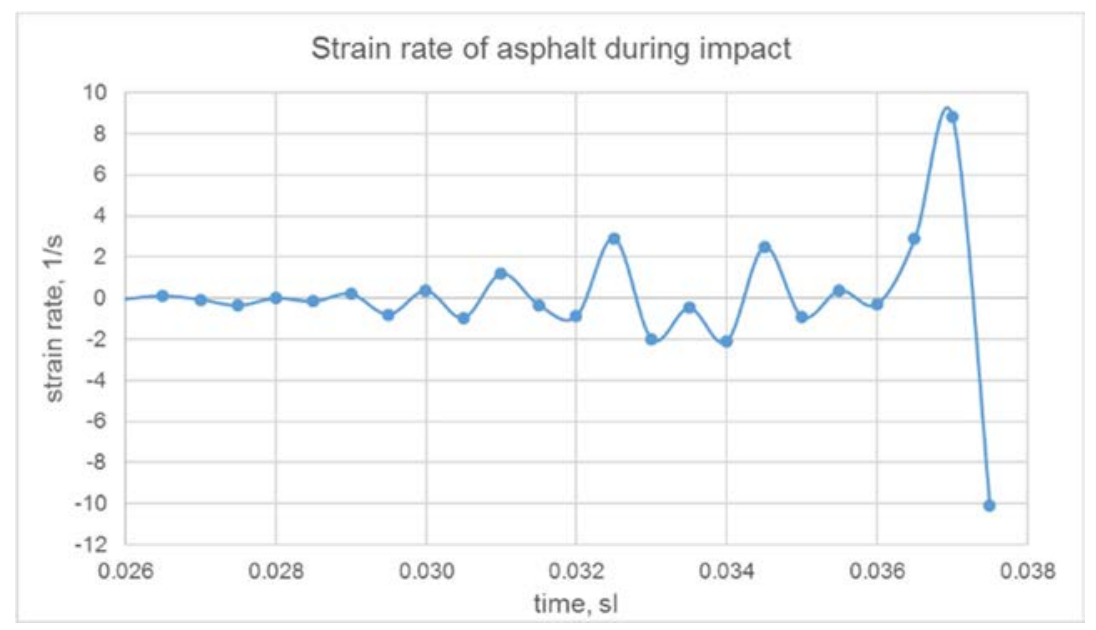

Figure 10: Strain rate of asphalt at impact velocity of $215 \mathrm{~m} / \mathrm{s}$. 
Another case of the material model sensitivity study was the use of the K\&C model instead of the Drucker-Prager model for the asphalt concrete. The asphalt layer is modelled as concrete with compressive strength of $f_{c}=48 \mathrm{MPa}$. The static tensile strength of asphalt concrete is assumed to be at $f_{t}=2.4 \mathrm{MPa}$ [15]. The strain rate sensitivity enhancement was included by using the dynamic increase factor from [16]. For compression:

$$
D I F=1.86+0.1432 \log _{10} \dot{\varepsilon} \text { for } \dot{\varepsilon} \leq 15 s^{-1} .
$$

The erosion strain was set to $10 \%$.

The use of the $\mathrm{K} \& \mathrm{C}$ model for the asphalt concrete caused much higher damage to the asphalt layer, than with the Drucker-Prager model. At the impact velocity of $190 \mathrm{~m} / \mathrm{s}$ a large area of asphalt is damaged (eroded), so that the concrete structure was subjected to higher deformation. However, it had no big impact on the fuel penetration.

\subsection{Airplane structure material model}

To evaluate the sensitivity of the analysis results to the material models of the airplane, the Johnson-Cook model was substituted by the bilinear model with the Cowper-Symonds strain rate parameters (MAT_PLASTIC_KINEMATIC, MAT003 in LS-DYNA). This model, which was used in the earlier analyses [1], can be computationally less expensive than the Johnson-Cook model.

The flow stress and the fracture strain are determined from

$$
\sigma=\left(\sigma_{0.2}+B \varepsilon\right)\left(1+\left(\frac{\dot{\varepsilon}}{c}\right)^{\frac{1}{p}}\right)
$$

The rate independent yield stress $\mathrm{A}=370 \mathrm{MPa}$ and hardening coefficient $\mathrm{B}=700 \mathrm{MPa}$ were obtained by fitting the strain-stress curve of 2024-T3 alloy at low strain rate (Fig. 11). The Cowper-Symonds model parameters $C=6500 / \mathrm{s}$ and $p=4$ were taken from [3].

The analysis results show no evident difference of the damage pattern of the impact area. The resultant amount of penetrated fuel is nearly the same.

\subsection{Element erosion criteria}

The erosion criterion was relaxed for the airplane structure. The failure strain $\varepsilon_{\text {fmin }}$ in the Johnson-Cook model for the Al-alloy was increased from 0.2 to 0.3 . The inclination of the stress-strain curve was slightly decreased to keep the rupture stress at the same level (Fig. 11).
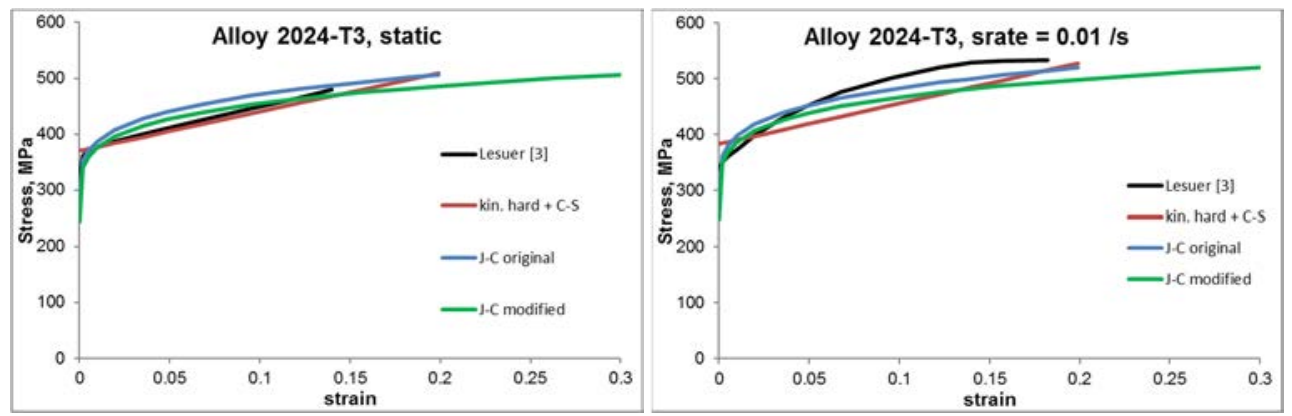

Figure 11: Stress-strain curves for 2024-T3 alloy. 
The results showed slightly lower damage of the concrete structure. This can be explained by the fact that with a higher failure strain more energy dissipates by the deformation of the plane structure leaving less energy for the impact. No significant effect on the fuel penetration was established.

The erosion criterion for the building structure proved to have a more important effect. The critical strain for the asphalt concrete was changed from 0.1 to 0.5 , which is same as the erosion strain of the reinforced concrete. The increase of the rupture strain resulted in practically undamaged asphalt layer and thus no penetration of fuel and debris.

The same strong effect was observed while decreasing the erosion strain for the concrete material from 0.5 to 0.1 . It leads to a strong damage of the concrete structure with an open penetration hole. The fuel penetration is increased by factor of 30 .

\subsection{Other analysis parameters}

The original contact definition of CONTACT_ERODING_SINGLE_SURFACE for all parts was modified. The contact between the airplane and the building structure was changed to CONTACT_ERODING_SURFACE_TO_SURFACE, while the contact between the airplane elements remained as CONTACT_ERODING_SINGLE_SURFACE. The results showed slightly lower damage of the concrete structure with the new contact definition. However, that does not have big effect on the amount of penetrated fuel.

The effect of the friction between the airplane and the structure was investigated for the inclined impact at $60^{\circ}$. In literature, use of friction coefficients between 0.4 [17] and 0.5 [2] is reported. In this study, the friction coefficient was increased from 0.5 to 1.0. The results show no significant influence of friction on the damage of the structure. The concrete slab as well as the asphalt layer remain almost undamaged with no fuel penetration into the building.

\section{CONCLUSIONS}

- The sensitivity studies of the postulated impact of F4 Phantom airplane on the underground radioactive waste structure show strong dependence of the kerosene penetration on the impact velocity. Critical impact velocity for the fuel penetration, local fire initiation and vast fire initiation were calculated.

- The impact angle close to the perpendicular is essential on the occurrence of significant fuel penetration. At more realistic impact angles no fire inside the building could occur.

- The results of the analyses show different sensitivity to material models of the concrete, asphalt and airplane structure. No major effect of the concrete material model was observed as long as the material parameters are based on the same concrete strength and erosion strain.

- Some analyses parameters like erosion criterion have big impact on the damage of the structure and fuel penetration. The analyses results showed less sensitivity to the friction coefficient and contact definition.

- $\quad$ The presented simulations studies have limited experimental validation background. While the F4 airplane crash on the RC structure was validated with the SANDIA Lab impact test and the RC behaviour at impact has been tested within IRIS programme [4], experimental studies on the impact resistance of RC structures covered with asphalt concrete and the post-impact behaviour in terms of penetration and dispersion of fuel and debris are still very limited. Nevertheless, conservative assumptions regarding the estimation of the asphalt concrete strength and assessment of the penetrated fuel amount can be applied, which allows to obtain useful results for fire risk assessment purposes. 


\section{REFERENCES}

[1] Nykyforchyn, A., Miloshev, M., Kostov, M., Steiner, P., \& Klügel, J.-U., Analysis of the consequences of an airplane crash on an underground radioactive waste storage building. Part I: Structural analysis. Proceedings of the 24th Conference on Structural Analysis in Reactor Technology, Busan, South Korea, 2017.

[2] Kostov, M., Miloshev, M., Nikolov, Z. \& Klecherov, I., Non-structural mass modelling in aircraft impact analysis. Proceedings of the 23rd Conference on Structural Analysis in Reactor Technology, Manchester, 2015.

[3] Lesuer, D.R., Experimental investigations of material models for Ti-6Al-4V Titanium and 2024-T3 Aluminum. Report DOT/FAA/AR-00/25, Lawrence Livermore National Laboratory, 2000.

[4] OECD, Improving robustness assessment methodologies for structures impacted by missiles (IRIS_2012). Report NEA/SCNI/R5-ADD1, OECD: Paris, 2014.

[5] Seibi, A., Constitutive relations for asphalt concrete under high rates of loading. Transportation Research Record: Journal of the Transportation Research Board, 1767, 2001.

[6] Zhang, Y. et al., A comprehensive characterization of asphalt mixtures in compression. Report 600451-00006-1, Texas A\&M Transportation Institute, 2013.

[7] Cox, B., The effect of asphalt content and temperature on the triaxial properties of an asphalt concrete mix. PhD thesis, Georgia Institute of Technology, 1960.

[8] Hopkins, T. et al., Bearing capacity analysis and design of highway base materials reinforced with geofabrics. Research report, Kentucky Transportation Center, 2005.

[9] Pellinen, T.K. et al., Characterization of hot mix asphalt with varying air voids content using triaxial shear strength test. Proceedings of the 8th Conference on Asphalt Pavements for Southern Africa CAPSA'04, Sun City, South Africa, 2004.

[10] Erkens, S. \& Poot, M., Determining and modeling asphalt concrete response. HERON, 45(3), pp. 219-236, 2000.

[11] Wu, Y., Crawford, J., Lan, S. \& Magallanes, J., Validation studies for concrete constitutive models with blast test data. Proceedings of the 13th Int. LS-DYNA Users Conference, Dearborn, MI, USA, 2014.

[12] Winkelbauer, B.J., Phase I evaluation of selected concrete material models in LSDYNA. MSc thesis, University of Nebraska, 2015.

[13] Crawford, J.E., Magallanes, J.M., Lan, S. \& Wu, Y., User's manual and documentation for Release III of the K\&C Concrete Material Model in LS-DYNA. Report TR-1136.1, Karagozian \& Case: Burbank, CA, 2011.

[14] CEB-FIP Model Code 90, Trowbridge, UK, 1990.

[15] Kennedy, T., Tensile characterization of highway pavement materials. Report FHWA/TX-84/21+183-15F, University of Texas, Austin, 1983.

[16] Wu, J. \& Liu, X., Performance of soft-hard-soft (SHS) cement based composite subjected to blast loading with consideration of interface properties. Frontiers of Structural and Civil Engineering, 9(3), pp. 323-340, 2015.

[17] Siefert, A. \& Henkel, F.O., Validation of integral crash simulation method by Sandia Test results for Phantom F4. Proceedings of the 23rd Conference on Structural Analysis in Reactor Technology, Manchester, UK, 2015. 